\title{
Inclusion of peak expiratory flow for selection of the 'best' forced vital capacity manoeuvre
}

\author{
Francesco Di Pede bs, Francesco Pistelli mD, Giovanni ViegI MD, PaOlo PaOletTI MD, \\ AlessandRo Celi MD, LAURA CARROZZI MD, MARIELLA VelLutinI MD, GIUSEPPE PISTELLI MD, \\ CARLO GIUNTINI MD \\ CNR Institute of Clinical Physiology and 2nd Division of Internal Medicine, University and \\ Hospital of Pisa, Pisa, and Ely Lilly, Firenze, Italy
}

F Di Pede, F Pistelli, G Viegi, et Al. Inclusion of peak expiratory flow for selection of the 'best' forced vital capacity manoeuvre. Can Respir J 1996;3(5):301308.

OBJECTIVE: To assess four different criteria for selecting the 'best' forced vital capacity (FVC) manoeuvre to be used for clinical diagnostic purposes.

DESIGN: Criterion standard.

SETTING: General population survey performed in 1980-82.

PATIENTS: One thousand, two hundred and eighty-three subjects (age range eight to 64 years) were first stratified into five mutually exclusive groups according to the following criteria: simultaneous largest FVC, forced expiratory volume in $1 \mathrm{~s}\left(\mathrm{FEV}_{1}\right)$ and peak expiratory flow (PEF) (group 1; $\mathrm{n}=481$ ); isolated largest $\mathrm{FVC}$ (group 2; $\mathrm{n}=223$ ); isolated largest $\mathrm{FEV}_{1}$ (group 3; $\mathrm{n}=144$ ); isolated largest PEF (group 4; $\mathrm{n}=299$ ); and overlapping criteria (group 5; $\mathrm{n}=136$ ).

INTERVENTION: Subjects performed spirometry following American Thoracic Society (ATS) protocol and filled out a standardized respiratory questionnaire.

MAIN OUTCOME MEASURES: Spirograms were analyzed by examining the frequency of spirometry abnormalities with regard to the presence of respiratory symptoms, first within mutually exclusive groups of subjects and then within the whole sample. The hypothesis of the role of PEF in 'best test' selection was formulated after data collection. MAIN RESULTS: When the isolated largest PEF criterion was used, the following data were obtained: the highest prevalence of spirometric abnormalities for each FVC parameter in each mutually exclusive group; the highest predictive value for mean and instantaneous expiratory flows in separating symptomatic from asymptomatic subjects; and finally, using the whole sample, higher levels of sensitivity and similar specificity to other criteria for all test parameters (all over 90\%, except for PEF).

CONCLUSIONS: While maintaining the current ATS criteria of acceptability and variability for FVC trials, it is proposed that the curve that better reflects maximal expiratory effort, ie, that with the largest PEF, be recorded and analyzed for spirometric variables.

Key Words: Epidemiology, Forced vital capacity manoeuvre, Forced vital capacity selection, Peak expiratory flow rate, Respiratory symptoms, Standardization

Inclusion du débit expiratoire de pointe pour la sélection de la « meilleure » épreuve de capacité vitale forcée

OBJECTIF : Évaluer quatre différents critères pour sélectionner la «meilleure » épreuve de capacité vitale forcée pouvant être utilisée à des fins de diagnostic clinique.

voir page suivante 
MODÈLE : Suivant la norme du critère.

CONTEXTE : Enquête dans la population générale menée entre 1980 et 1982.

PATIENTS : En premier lieu, on a procédé à la stratification en cinq groupes mutuellement exclusifs de 1283 sujets (âgés de 8 à 64 ans) selon les critères suivants : meilleure capacité vitale forcée (CVF) simultanée, volume expiratoire maximum/seconde (VEMS) et débit expiratoire de pointe (DEP) (groupe $1 ; n=481$ ); meilleure CVF isolée (groupe 2; n=223); meilleur VEMS isolé (groupe 3; $n=144$ ); meilleur DEP isolé (groupe $4 ; n=299$ ); et critères se chevauchant (groupe $5 ; \mathrm{n}=136$ ).

INTERVENTION : Les sujets ont réalisé des épreuves spirométriques selon le protocole de l'American Thoracic Society (ATS) et ont rempli un questionnaire standardisé sur la respiration.

PRINCIPALES MESURES DES RÉSULTATS : Les spirogrammes ont été analysés en examinant la fréquence des anomalies spirométriques relativement à la présence de symptômes respiratoires, en premier à l'intérieur des groupes de sujets mutuellement exclusifs puis, dans l'échantillon entier. L'hypothèse du rôle du DEP dans la sélection du « meilleur test »a été formulée après la collecte des données.

PRINCIPAUX RÉSULTATS : Quand on a utilisé le critère du meilleur DEP isolé, on a obtenu les données suivantes: la prévalence la plus élevée d'anomalies spirométriques pour chaque paramètre de CVF dans chacun des groupes mutuellement exclusifs, la plus forte valeur prédictive pour les débits expiratoires moyens et instantanés en séparant les sujets symptomatiques des sujets asymptomatiques; finalement, en utilisant la totalité de l'échantillon, des niveaux de sensibilité plus élevés et une spécificité similaire aux autres critères pour tous les paramètres du test (tous supérieurs à $90 \%$, sauf pour le DEP).

CONCLUSIONS : Tout en conservant les critères courants d'acceptabilité et de variabilité de l'ATS pour les essais de CVF, on propose que la courbe qui reflète le mieux l'effort expiratoire maximal, c'est-à-dire, avec le meilleur débit de pointe, soit notée et analysée pour obtenir les variables spirométriques.
$\mathrm{D}$ espite general agreement on the American Thoracic Society (ATS) definition of forced vital capacity (FVC) as "the maximal volume of air exhaled with maximally forced effort from a position of maximal inspiration" (1-3), the standardization of the manoeuvre has proven to be difficult. A number of issues related to the performance and analysis of the test have been discussed in numerous papers, dealing with determination of the starting point (back extrapolation) $(1,4)$ and of the end-point $(2,5)$ of the spirogram; criteria for acceptability and reproducibility $(1-3,6,7)$; selection of the best spirometric values (8); and effects of thoracic gas compression $(9,10)$.

One of the remaining controversial problems relates to the selection of the 'best' curve, ie, the flow-volume curve from which mean and instantaneous expiratory flows are obtained $(2,4)$. The Intermountain Thoracic Society (11) recommended that all the parameters, including FVC and forced expiratory volume in $1 \mathrm{~s}\left(\mathrm{FEV}_{1}\right)$, should be obtained from the curve with the largest sum of FVC plus FEV 1 . In the guidelines published by the ATS in 1979 (1) and, in revised form, in 1987 (2) and in 1995 (3), it was recommended that the largest FVC and the largest $\mathrm{FEV}_{1}$ be recorded, even when obtained from different manoeuvres, and that the manoeuvre with the largest sum of FVC plus FEV 1 (ie, the ATS 'best test' curve) be used to calculate the mean and instantaneous forced expiratory flows. Recently the European Respiratory Society published a document on the standardization of lung function measurements, which contains the proposal that two alternative methods be used to obtain flow-volume indexes: "the first one (envelope method) entails superimposing the curves from total lung capacity (TLC) to form a composite maximal curve; the largest FVC curve is used to delineate the highest instantaneous flows at specified lung volumes. The second method is to take the highest instantaneous flow from three technically satisfactory FVC manoeuvres; the FVC from the chosen flow-volume curves should not differ from the largest FVC by more than 5\%" (12). Thus, none of the current criteria for the selection of the flow-volume curve from which the FVC parameters are calculated recommends that peak expiratory flow (PEF) be taken into account.

The flow-volume curve including the largest PEF should meet the ATS definition of FVC, since an FVC manoeuvre cannot be considered really 'forced' if the maximal expiratory effort (ie, with a satisfactory start of the spirogram and high PEF) is not achieved.

Submaximal efforts (indicated by a slow start to the spirogram and low PEF) can result in either higher or lower FEV 1 values than maximal efforts $(3,9,13)$ due to less dynamic compression of airways or failure to reach a maximal TLC, respectively. Based on the current ATS criteria, computercontrolled routines should select mean and instantaneous expiratory flows from the 'best test', whether performed with maximal or with submaximal effort; the latter may result in an incorrect clinical interpretation. In fact, abnormalities of mean and instantaneous expiratory flows are not usually taken into account when $\mathrm{FEV}_{1}$ and $\mathrm{FEV}_{1}$ /vital capacity percentage $\left(\mathrm{FEV}_{1} / \mathrm{VC} \%\right)$ are within the expected range (14). Nevertheless, in the presence of a borderline value for $\mathrm{FEV}_{1} / \mathrm{VC} \%$, they may help to confirm the presence of airway obstruction, even taking into account the wide intraindividual variability present in normal subjects (14).

The aim of our study was to assess whether a different criterion for the selection of the 'best test' curve, based on the FVC manoeuvre performed with the maximal PEF, may further enhance the diagnostic power of this test. This method was compared with ATS criteria by examining the frequency of abnormalities in FVC parameters in relation to the presence of respiratory symptoms.

\section{PATIENTS AND METHODS}

Data set: FVC tracings were acquired during the first crosssectional epidemiological survey conducted in 1980-82 on a general population sample $(\mathrm{n}=3285,47.9 \%$ males, age range eight to 64 years) living in the Po River Delta area (20 km south of Venice, Italy). The study protocol included acquisition of the following respiratory data: FVC; slow vital capacity; single breath diffusing capacity; single breath nitrogen 
test (closing volume); and standard questionnaire for respiratory symptoms, diseases and risk factors. This study has been extensively described previously (15-18).

Questionnaire: A modified Italian version of the National Heart, Lung, and Blood Institute questionnaire (17) was developed by the Special Project on Chronic Obstructive Pulmonary Disease of the Italian National Research Council (CNR): CNR Questionnaire on Respiratory Symptoms, Diseases and Risk Factors. The following main sections were included: general anthropometric and health information; presence of respiratory symptoms (cough, phlegm, effort dyspnea, attacks of shortness of breath with wheeze, wheezing during and apart from common colds); presence of cardiac or pulmonary disease (chronic bronchitis, emphysema, asthma, heart disease, etc); presence of rhinitis or allergic disorders; presence of childhood respiratory disease; presence of family histories of asthma, chronic bronchitis, emphysema, tuberculosis, lung cancer, atopy or allergies; occupational exposure and smoking history; and socioeconomic information. Trained nurses administered the questionnaire using standard protocol.

Subjects were considered to be symptomatic if they answered affirmatively to any question referring to respiratory symptoms or diseases. Subjects who answered affirmatively to standard questions regarding a diagnosis of chronic bronchitis and/or pulmonary emphysema were defined as suffering from chronic obstructive pulmonary disease (COPD).

Spirometry: A computerized pneumotachograph (Pulmonary System 47804S, Hewlett-Packard, Massachusetts) was used for the acquisition and on-line analysis of lung function data during the field survey. The system consisted of a Fleisch pneumotachograph number 3 (Hewlett-Packard) for flow measurements, linked via an analogue to digital (A/D) Converter (47310A-HP) to a 9825 A Hewlett-Packard calculator (HP 9825, California). In this system the pressure change, induced by the respiratory flow passing through the pneumotachograph, was translated into millivolts. The A/D converter digitized the measured millivolts and the computer integrated the volume signal from the flow signal. Pneumotachograph response was linear $( \pm 3 \%$ between 1 and $13 \mathrm{~L} / \mathrm{s})$. The volume of the pneumotachograph was calibrated daily with a $3.0 \mathrm{~L}$ standard syringe. Because these studies were carried out before international standardization of flow measurements, the system was recently tested during a range of flow rates, between 1.61 and $7.56 \mathrm{~L} / \mathrm{s}$, generated by a standard decompressive pump and four resistances. The percentage variation between repeated readings among resistors was between $0.70 \%$ and $1.83 \%(0.03$ to $0.08 \mathrm{~L} / \mathrm{s})$, well within the $5 \%$ or $0.15 \mathrm{~L} / \mathrm{s}$ recommended by Crapo et al (3). Accuracy of readings compared with measurements made with a watersealed spirometer varied between $0.3 \%$ and $3.5 \%$, with maximum differences of 0.04 and $0.22 \mathrm{~L} / \mathrm{s}$.

Each subject performed at least three acceptable and reproducible FVC manoeuvres, as specified by ATS protocol; the end-point of the FVC manoeuvre was determined using feedback requiring consecutive samples to determine a flow of less than $15 \mathrm{~mL} / \mathrm{s}$, and no time limitation was imposed by
TABLE 1

Sample spirometric data for one individual from each of five mutually exclusive study groups

\begin{tabular}{|c|c|c|c|c|c|}
\hline \multirow[b]{2}{*}{ Subject } & \multicolumn{3}{|c|}{ Results of 3 trials } & \multirow{2}{*}{$\begin{array}{l}\text { Selected } \\
\text { curve }\end{array}$} & \multirow[b]{2}{*}{ Criteria } \\
\hline & FVC & FEV $_{1}$ & PEF & & \\
\hline \multirow[t]{3}{*}{1} & 3.81 & 3.13 & 7.63 & & \\
\hline & 3.78 & 3.12 & 7.21 & & \\
\hline & $\underline{3.90}$ & $\underline{3.23}$ & $\underline{7.73}$ & Group 1 & $\begin{array}{c}\text { Simultaneous } \\
\text { largest FVC, FEV } 1 \\
\text { and } \mathrm{PEF}\end{array}$ \\
\hline \multirow[t]{3}{*}{2} & $\underline{3.27}$ & $\underline{2.23}$ & 5.48 & ATS- $\Sigma$ & Largest FVC+FEV 1 \\
\hline & 3.26 & 2.16 & 5.01 & & \\
\hline & $\underline{3.31}$ & 2.17 & 4.88 & Group 2 & $\begin{array}{c}\text { Isolated largest } \\
\text { FVC }\end{array}$ \\
\hline \multirow[t]{3}{*}{3} & $\underline{5.49}$ & $\underline{4.66}$ & 10.08 & ATS- $\Sigma$ & Largest FVC+FEV \\
\hline & 5.36 & $\underline{4.73}$ & 11.32 & Group 3 & $\begin{array}{c}\text { Isolated largest } \\
\text { FEV }_{1}\end{array}$ \\
\hline & 5.41 & 4.65 & 10.03 & & \\
\hline \multirow[t]{3}{*}{4} & $\underline{2.95}$ & $\underline{2.22}$ & 6.21 & ATS- $\Sigma$ & Largest FVC+FEV 1 \\
\hline & 2.89 & 2.22 & 6.12 & & \\
\hline & 2.92 & 2.19 & $\underline{6.23}$ & Group 4 & $\begin{array}{c}\text { Isolated largest } \\
\text { PEF }\end{array}$ \\
\hline \multirow[t]{3}{*}{5} & $\underline{3.18}$ & $\underline{2.34}$ & 5.26 & ATS- $\Sigma$ & Largest FVC+FEV 1 \\
\hline & $\underline{3.20}$ & 2.24 & 4.92 & (Group 2) & $\begin{array}{c}\text { Isolated largest } \\
\text { FVC }\end{array}$ \\
\hline & 3.17 & 2.26 & $\underline{5.64}$ & (Group 4) & $\begin{array}{c}\text { Isolated largest } \\
\text { PEF }\end{array}$ \\
\hline
\end{tabular}

$\overline{A T S-\Sigma}$ American Thoracic Society (ATS) 'best test' curve (ie, the curve with the largest result of forced vital capacity [FVC] + forced expiratory volume in $1 \mathrm{~s}$ [FEV 1$]$ ) for subjects who had an alternative criterion for the selection of the 'best' FVC manoeuvre; PEF Peak expiratory flow. Underlined values were used for the selection of the group and of the ATS- $\Sigma$ curve. Subjects 1 to 4 were assigned to groups 1 to 4 according to the hierarchically and mutually exclusive presence of selection criteria. Subject 5 showed the largest values of FVC, FEV 1 and PEF in three different curves, and was thus included in group 5 and excluded from the subsequent analyses

the algorithm (5). There was no limit to the number of acquirable FVC manoeuvres. For each FVC manoeuvre, the following parameters were obtained: $\mathrm{FVC} ; \mathrm{FEV}_{1}$; forced expiratory flow between $25 \%$ and $75 \%$ of $\mathrm{FVC}\left(\mathrm{FEF}_{25-75 \%}\right)$; forced expiratory flow between $75 \%$ and $85 \%$ of FVC (FEF $75-85 \%)$; maximal expiratory flow at $50 \%$ of FVC (MEF50\%); maximal expiratory flow at $75 \%$ of FVC (MEF75\%); and PEF.

Group analyses: Spirometric tracings of 1283 subjects were reviewed and grouped first according to selection criteria and then to the total group.

Analyses applied to mutually exclusive groups: Following a hierarchic priority order, each subject was assigned to one of five groups, according to the following criteria for 'best' curve selection: largest FVC, $\mathrm{FEV}_{1}$ and $\mathrm{PEF}$ in the same curve, thus including ATS criteria for selection of the curve to be used for diagnostic purposes (group 1); largest FVC in a different curve from the one with the largest sum of FVC and $\mathrm{FEV}_{1}$ (group 2); largest $\mathrm{FEV}_{1}$ in a different curve from the one with the largest FVC and from the one with the largest sum of FVC and $\mathrm{FEV}_{1}$ (group 3); isolated largest PEF in a different curve from those characterizing the previous three 
TABLE 2

Main characteristics of the five mutually exclusive study groups

\begin{tabular}{lcccccc}
\hline Characteristic & Group 1 & Group 2 & Group 3 & Group 4 & Group 5 & Total \\
\hline Number & 481 & 223 & 144 & 299 & 136 & 1283 \\
Age (mean years \pm SD) & $33.9 \pm 16.1$ & $35.4 \pm 15.9$ & $34.0 \pm 15.7$ & $36.1 \pm 16.4$ & $35.2 \pm 16.4$ & $34.8 \pm 16.1$ \\
Height (mean cm \pm SD) & $161.8 \pm 10.8$ & $163.0 \pm 11.1$ & $162.3 \pm 10.9$ & $161.9 \pm 10.3$ & $161.6 \pm 10.3$ & $162.1 \pm 10.7$ \\
Weight (mean kg \pm SD) & $66.0 \pm 15.8$ & $65.4 \pm 13.8$ & $63.5 \pm 13.6$ & $65.7 \pm 15.2$ & $64.6 \pm 13.3$ & $65.0 \pm 16.3$ \\
Male (\%) & 48.2 & 48.4 & 49.3 & 46.8 & 47.0 & 47.9 \\
Female (\%) & 51.8 & 51.6 & 50.7 & 53.2 & 53.0 & 52.1 \\
Nonsmokers (\%) & 49.5 & 49.3 & 54.9 & 46.1 & 50.0 & 49.3 \\
Smokers (\%) & 37.8 & 37.2 & 32.6 & 38.5 & 40.4 & 37.6 \\
Ex-smokers (\%) & 12.7 & 13.5 & 12.5 & 15.4 & 13.1 \\
\hline
\end{tabular}

There were no statistically significant differences among the mutually exclusive groups for any anthropometric mean value by ANOVA, nor for sex or smoking habit by $\chi^{2}$ test

TABLE 3

Flow-volume curve parameters in the first four study groups

\begin{tabular}{|c|c|c|c|c|c|c|c|}
\hline \multirow[b]{2}{*}{ Parameter } & \multirow{2}{*}{$\begin{array}{l}\text { Group } 1(n=481) \\
>\text { FVC, } \text { FEV } 1, \text { PEF }\end{array}$} & \multicolumn{2}{|c|}{ Group 2 (n=223) } & \multicolumn{2}{|c|}{ Group $3(n=144)$} & \multicolumn{2}{|c|}{ Group 4 (n=299) } \\
\hline & & ATS- $\Sigma$ & $>$ FVC & ATS- $\Sigma$ & $>\mathrm{FEV}_{1}$ & ATS- $\Sigma$ & >PEF \\
\hline $\mathrm{FVC}($ mean $\mathrm{L} \pm \mathrm{SD})$ & $3.92 \pm 1.00$ & $4.06 \pm 1.08$ & $4.11^{*} \pm 1.10$ & $\underline{4.03} \pm 1.09$ & $3.95^{* *} \pm 1.07$ & $\underline{3.87} \pm 0.99$ & $3.80^{* *} \pm 0.99$ \\
\hline $\mathrm{FEV}_{1}($ mean $\mathrm{L} \pm \mathrm{SD})$ & $3.07 \pm 0.79$ & $\underline{3.25} \pm 0.85$ & $3.12^{* *} \pm 0.84$ & $3.07 \pm 0.79$ & $\underline{3.10}^{* *} \pm 0.80$ & $\underline{3.05} \pm 0.81$ & $2.98^{\star *} \pm 0.80$ \\
\hline $\mathrm{FEF}_{25-75 \%}($ mean L/s $\pm \mathrm{SD})$ & $3.23 \pm 1.14$ & $\underline{3.36} \pm 1.09$ & $3.28^{* *} \pm 1.08$ & $3.19 \pm 1.10$ & $\underline{3.24}{ }^{*} \pm 1.08$ & $\underline{3.24} \pm 1.18$ & $3.14^{\star *} \pm 1.18$ \\
\hline $\mathrm{FEF}_{75-85 \%}($ mean L/s $\pm \mathrm{SD})$ & $1.10 \pm 0.62$ & $\underline{1.16} \pm 0.63$ & $1.10^{* *} \pm 0.64$ & $1.09 \pm 0.63$ & $\underline{1.16}^{\star *} \pm 0.65$ & $\underline{1.09} \pm 0.62$ & $1.05^{\star *} \pm 0.64$ \\
\hline MEF50\% ( mean L/s \pm SD) & $3.90 \pm 1.31$ & $\underline{4.05} \pm 1.22$ & $3.98^{*} \pm 1.28$ & $3.83 \pm 1.24$ & $\underline{3.90} \pm \pm 1.20$ & $\underline{3.95} \pm 1.33$ & $3.82^{\star *} \pm 1.35$ \\
\hline MEF75\% ( mean L/s $\pm S D)$ & $1.53 \pm 0.76$ & $\underline{1.60} \pm 0.74$ & $1.52^{* *} \pm 0.71$ & $1.51 \pm 0.74$ & $1.56 * \pm 0.76$ & $\underline{1.52} \pm 0.76$ & $1.46^{\star \star} \pm 0.76$ \\
\hline $\mathrm{PEF}($ mean L/s $\pm \mathrm{SD})$ & $6.80 \pm 1.99$ & $\underline{7.08} \pm 2.06$ & $6.91^{* *} \pm 2.06$ & $6.74 \pm 2.02$ & $\underline{6.81^{*}} \pm 1.98$ & $6.54 \pm 1.88$ & $7.03^{\star *} \pm 1.96$ \\
\hline
\end{tabular}

ATS- $\Sigma$ American Thoracic Society (ATS) 'best test' curve (ie, the curve with the largest result of forced vital capacity [FVC] + forced expiratory volume in $1 \mathrm{~s}\left[F E V_{1}\right]$ ) for subjects who had an alternative criterion for the selection of the 'best' $F V C$ manoeuvre; FEF $25-75 \%$ Forced expiratory flow between $25 \%$ and $75 \%$ of FVC; FEF $75-85 \%$ Forced expiratory flow between $75 \%$ and $85 \%$ of FVC; MEF50\% Maximal expiratory flow at $50 \%$ of FVC; MEF75\% Maximal expiratory flow at $75 \%$ of FVC; PEF Peak expiratory flow. $>F V C, F E V_{1}, P E F$ is defined as the simultaneous largest FVC, FEV 1 and PEF criterion (including ATS criteria for selection of the curve to be used for diagnostic purposes); $>F V C$ is defined as isolated largest $F V C$ criterion; $>F E V_{1}$ is defined as isolated largest FEV 1 criterion; $>P E F$ is defined as isolated largest PEF criterion. The highest value found for each parameter in groups 2 to 4 is underlined. ${ }^{*} P<0.05 ;{ }^{* *} P<0.01$ by paired $t$ test

groups (group 4); and more than one of the selection criteria for groups 2, 3 and 4 simultaneously present in the three curves (group 5). The assignment of subjects to groups followed this priority order (from group 1 to group 4); thus, for example, a subject was included in group 3 if the largest $\mathrm{FEV}_{1}$ and the largest PEF were present in the same curve. The criteria used to select groups were mutually exclusive; to illustrate this process, individual data from three spirograms, obtained in each of five subjects assigned to the five different groups, are shown in Table 1.

Analyses applied to the total group: Subsequently, all the 1147 subjects assigned to the first four mutually exclusive groups were used to constitute four categories, in which FVC parameters were derived from the curve with the largest sum of FVC plus FEV 1 , ie, the ATS 'best test' curve (category 1); the curve with the largest FVC (category 2); the curve with the largest $\mathrm{FEV}_{1}$ (category 3); and the curve with the largest PEF (category 4). Each criterion was applied to the whole sample of 1147 subjects; thus, in this analysis the four categories were not mutually exclusive.

Statistical analyses: Analyses were performed at the computer facilities of the University of Pisa and the CNR Computer Center-CNUCE using the Statistical Package for the
Social Sciences (SPSS/PC + Update, V3.0 and V3.1, SPSS Inc, Illinois). Analysis of variance was used to compare anthropometric parameters and the $\chi^{2}$ test to compare smoking categories. Paired $t$ test was used to compare intragroup mean values of FVC indexes, and a $t$ test for independent variables was used to compare sensitivity values among groups and categories. Each parameter of each group was classified as normal or abnormal if it was higher or lower, respectively, than the normal 95th percentile limit from prediction equations derived within the same general population sample (16). Sensitivity, specificity and predictive value were used to test the ability of the flow-volume curve parameters of different groups to discriminate between symptomatic and asymptomatic subjects (19).

\section{RESULTS}

No difference was present in sex, anthropometric parameters and smoking habits among the five mutually exclusive groups (Table 2).

In order to examine data without overlapping selection criteria, a number of analyses were performed on the first four groups ( $n=1147)$. First, the average for each of the seven parameters of the flow-volume curve obtained in each group 
Prevalence (\%) of spirometric abnormalities in the first four mutually exclusive study groups

\begin{tabular}{|c|c|c|c|c|c|c|c|}
\hline & \multirow{2}{*}{$\begin{array}{l}\text { Group } 1(n=481) \\
>\text { FVC, } \text { FEV } 1, \text { PEF }\end{array}$} & \multicolumn{2}{|c|}{ Group $2(n=223)$} & \multicolumn{2}{|c|}{ Group $3(n=144)$} & \multicolumn{2}{|c|}{ Group $4(n=299)$} \\
\hline & & ATS- $\Sigma$ & $>$ FVC & ATS- $\Sigma$ & $>\mathrm{FEV}_{1}$ & ATS- $\Sigma$ & $>\mathrm{PEF}$ \\
\hline FVC (L) & 7.3 & 5.8 & 5.4 & 2.1 & 5.6 & 5.7 & $\underline{8.4}$ \\
\hline $\mathrm{FEV}_{1}(\mathrm{~L})$ & 10.0 & 4.9 & 9.4 & 6.9 & 6.9 & 9.4 & 13.0 \\
\hline $\mathrm{FEF}_{25-75 \%}(\mathrm{~L} / \mathrm{s})$ & 12.3 & 8.1 & 8.1 & 9.0 & 7.6 & 8.7 & 11.7 \\
\hline $\mathrm{FEF}_{75-85 \%}(\mathrm{~L} / \mathrm{s})$ & 8.9 & 4.9 & 8.1 & 6.9 & 4.9 & 8.7 & $\underline{9.7}$ \\
\hline MEF50\% (L/s) & 14.8 & 11.2 & 12.6 & 16.0 & 13.2 & 14.7 & 19.4 \\
\hline MEF75\% (L/s) & 13.7 & 7.2 & 11.2 & 13.2 & 11.1 & 10.7 & 10.7 \\
\hline PEF & 19.8 & 15.2 & 23.3 & 24.3 & 19.4 & $\underline{30.1}$ & 15.1 \\
\hline
\end{tabular}

ATS- $\Sigma$ American Thoracic Society (ATS) 'best test' curve (ie, the curve with the largest result of forced vital capacity [FVC] + forced expiratory volume in $1 \mathrm{~s}\left[F E V_{1}\right]$ ) for subjects who had an alternative criterion for the selection of the 'best' $F V C$ manoeuvre; FEF $25-75 \%$ Forced expiratory flow between $25 \%$ and $75 \%$ of FVC; FEF $75-85 \%$ Forced expiratory flow between $75 \%$ and $85 \%$ of FVC; MEF50\% Maximal expiratory flow at $50 \%$ of FVC; MEF75\% Maximal expiratory flow at $75 \%$ of FVC; PEF Peak expiratory flow. $>F V C, F E V_{1}, P E F$ is defined as the simultaneous largest FVC, FEV 1 and PEF criterion (including ATS criteria for selection of the curve to be used for diagnostic purposes). The highest abnormality values shown by each parameter in groups 1 to 4 are underlined. Threshold value is the normal 95th percentile

TABLE 5

Sensitivity (\%), specificity (\%) and predictive value (\%) of FVC parameters for the presence of at least one respiratory symptom in the first four mutually exclusive study groups

\begin{tabular}{|c|c|c|c|c|c|c|c|c|c|c|c|c|}
\hline & \multicolumn{3}{|c|}{ Group 1 (n=481) } & \multicolumn{3}{|c|}{ Group $2(n=223)$} & \multicolumn{3}{|c|}{ Group $3(n=144)$} & \multicolumn{3}{|c|}{ Group 4 (n=299) } \\
\hline & Sens & Spec & PV & Sens & Spec & PV & Sens & Spec & PV & Sens & Spec & PV \\
\hline FVC (L) & 10.6 & 93.8 & 34.3 & 3.0 & 94.2 & 8.3 & 14.8 & $\underline{96.6}$ & $\underline{50.0}$ & 13.2 & 93.1 & 36.0 \\
\hline $\mathrm{FEV}_{1}(\mathrm{~L})$ & 23.0 & $\underline{94.0}$ & $\underline{54.2}$ & 15.2 & 91.6 & 23.8 & 11.1 & $\underline{94.0}$ & 30.0 & $\underline{27.9}$ & 91.3 & 48.7 \\
\hline $\mathrm{FEF}_{25-75 \%}(\mathrm{~L} / \mathrm{s})$ & $\underline{26.5}$ & 92.1 & 50.8 & 18.2 & $\underline{93.7}$ & 33.3 & 7.4 & 92.3 & 18.2 & $\underline{26.5}$ & 92.6 & $\underline{51.4}$ \\
\hline $\mathrm{FEF}_{75-85 \%}(\mathrm{~L} / \mathrm{s})$ & 17.7 & 93.8 & 46.5 & $\underline{27.3}$ & 95.3 & 50.0 & 7.4 & $\underline{95.7}$ & 28.6 & 23.5 & 94.4 & $\underline{55.2}$ \\
\hline MEF50\% (L/s) & $\underline{29.2}$ & 89.7 & 46.5 & 21.2 & 88.9 & 25.0 & 14.8 & 87.2 & 21.1 & 27.9 & $\underline{94.4}$ & $\underline{53.4}$ \\
\hline MEF75\% (L/s) & $\underline{28.3}$ & 90.8 & 48.5 & 24.2 & 91.1 & 32.0 & 14.8 & 89.7 & 21.1 & 27.9 & $\underline{94.4}$ & $\underline{59.4}$ \\
\hline PEF (L/s) & $\underline{35.4}$ & 85.1 & 41.1 & 33.3 & 78.4 & 21.1 & 22.2 & 81.2 & 21.4 & 32.4 & $\underline{90.0}$ & $\underline{48.9}$ \\
\hline
\end{tabular}

$F_{E F} 25-75 \%$ Forced expiratory flow between $25 \%$ and $75 \%$ of forced vital capacity ( $\left.F V C\right)$; $F E F_{75-85 \%}$ Forced expiratory flow between $75 \%$ and $85 \%$ of FVC; FEV 1 Forced expiratory volume in $1 \mathrm{~s}$; MEF $50 \%$ Maximal expiratory flow at $50 \%$ of FVC; MEF $75 \%$ Maximal expiratory flow at $75 \%$ of FVC; PEF Peak expiratory flow. The highest values for sensitivity (Sens), specificity (Spec) and predictive value (PV) reached by each parameter in groups 1 to 4 are underlined. Threshold value is the normal 95th percentile. Sensitivity differences between groups were not statistically significant by $t$ test

was compared with the average obtained by applying ATS criteria in that subgroup (Table 3). For group $1(\mathrm{n}=481 ; 42 \%)$ the parameters of only one curve were used because these subjects, comprising the largest group, showed the simultaneous presence of the largest $\mathrm{FVC}, \mathrm{FEV} 1$ and $\mathrm{PEF}$ in the same curve. For group $2(\mathrm{n}=223 ; 19 \%)$, group $3(\mathrm{n}=144$; $13 \%)$ and group $4(\mathrm{n}=299 ; 26 \%)$, all parameters differed significantly, as assessed by paired $t$ test, between curves selected using the ATS- $\Sigma$ (ie, the curve with the largest sum of FVC plus $F V_{1}$ ) and curves selected by the alternative criterion. Thus, larger mean values of all parameters were found in the ATS- $\Sigma$ curve in group 2 (with the obvious exception of FVC) and in group 4 (with the obvious exception of PEF), and in the curve of the alternative criterion for group 3 (with the exception of FVC).

The highest percentages of abnormal values (Table 4), using the normal 95th percentile as a threshold value, were shown by group 1 for $\mathrm{FEF}_{25-75 \%}$ and MEF $75 \%$, and by group 4 for $\mathrm{FVC}, \mathrm{FEV}_{1}, \mathrm{FEF}_{75-85 \%}$ and MEF50\%. As regards PEF, the highest frequency of abnormality, as assessed by the ATS- $\Sigma$ curve, was shown by group 4 .
Table 5 shows the sensitivity, specificity and predictive values of parameters derived from the flow-volume curve in detecting symptomatic subjects, ie, those with at least one respiratory symptom. The highest sensitivity with regard to $\mathrm{FEV}_{1}$ was shown by group 4, while the highest specificity for the same parameter was present in groups 1 and 3. Furthermore, the highest sensitivity for mean and instantaneous expiratory flows (except FEF75-85\%) was exhibited by group 1, followed by group 4; the latter showed the same sensitivity value for $\mathrm{FEF}_{25-75 \%}$ as group 1 and the highest specificity values for MEF50\%, MEF $75 \%$ and PEF. Moreover, the highest sensitivity and specificity values for FVC were shown by group 3, who had also the highest specificity for FEF $75-85 \%$, while the highest sensitivity for this parameter was demonstrated by group 2 . The highest predictive values for FVC (50\%) and $\mathrm{FEV}_{1}(54.2 \%)$ were reached by groups 3 and 1 , respectively, followed by group 4 . The latter showed the highest predictive values for all mean and instantaneous expiratory flows and PEF (48.9\%). Differences in sensitivity between groups were not statistically significant by $t$ test.

Prevalence rates of respiratory symptoms and diseases are 


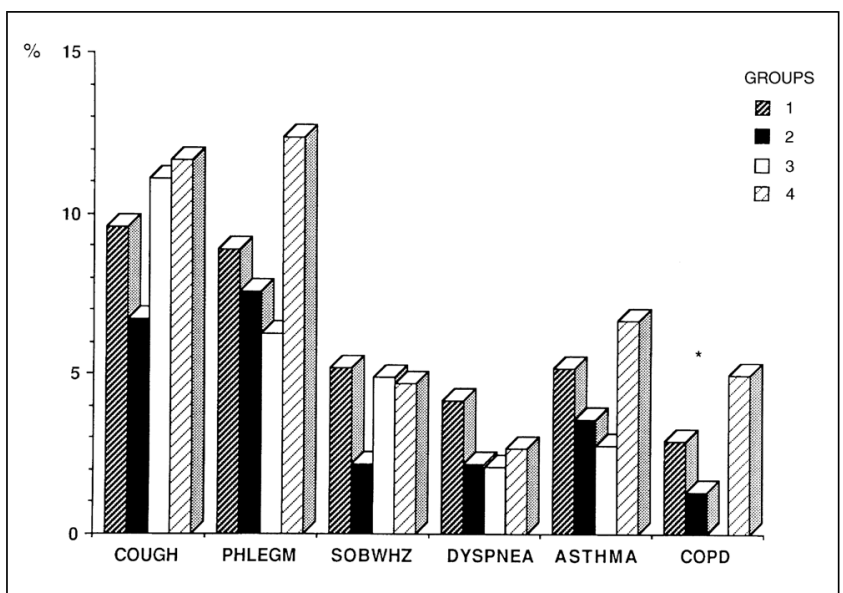

Figure 1) Prevalence rates of respiratory symptoms and diseases in four mutually exclusive groups. Group 1: simultaneous largest forced vital capacity $(F V C)$, forced expiratory volume in $1 \mathrm{~s}\left(F E V_{1}\right)$ and peak expiratory flow (PEF); Group 2: isolated largest FVC; Group 3: isolated largest FEV ; Group 4: isolated largest PEF. All prevalence rates were higher in group 4, except for attacks of shortness of breath with wheeze (SOBWHZ) and dyspnea, which where higher in group $1 .{ }^{*} P<0.05$ by $\chi^{2}$ test. COPD Chronic obstructive pulmonary disease

shown in Figure 1. All prevalence rates were higher in group 4, except for attacks of shortness of breath with wheeze and dyspnea, which were higher in group 1 . However, the difference among the rates was significant only for the diagnosis of COPD.

Results of analyses performed on the four categories, each constituted from the whole sample of 1147 subjects, are shown in Table 6. The highest sensitivity for all FVC parameters, except MEF75\% and PEF, was present in category 4. The sensitivity differences were not statistically significant among the four categories by $t$ test. As regards specificity, the highest values were exhibited by category 3 for all parameters, with the exception of FVC and PEF, the highest values for which were present in categories 2 and 4, respec- tively. The highest predictive values for FVC $(32.5 \%)$ and PEF $(39.0 \%)$ were reached by category 4 , while category 3 showed the highest predictive values for all the other parameters.

\section{DISCUSSION}

Several authors (20-22) have assessed the feasibility of using PEF rate as an index of a subject's effort during an FVC manoeuvre. Krowka et al (9) demonstrated "a significant positive correlation between PEF rate and the magnitude of the transpulmonary pressure-area product during the first second of the FVC manoeuvre." Results of large epidemiological studies (13) suggest that the use of PEF reproducibility may further enhance the technician's ability to detect poorly performed FVC manoeuvres. Also, the European Respiratory Society, in a 1993 document on the standardization of lung function (12), suggested the use of PEF reproducibility (within $10 \%$ of the maximal value) for computer selection of acceptable spirograms. Finally, very recently (3) the ATS encouraged investigators to measure time-to-PEF or rise-time of PEF when assessing a subject's correct performance of FVC manoeuvres.

Parameters obtained from FVC manoeuvres in which the largest PEF occurs should reflect performance associated with maximal effort. Thus, the inclusion of this criterion might improve the clinical interpretation of the FVC test; indeed, our data show that different selection criteria for the 'best' curve lead to different values for several of the derived variables. In fact, within groups 2, 3 and 4, we observed statistically significant differences between values derived from the ATS- $\Sigma$ curve and those from spirograms selected by the alternative criterion. The differences in the four groups were not due to biases related to sex, or anthropometric or smoking characteristics, since these variables were not significantly different.

Most subjects were assigned to group 1 (largest FVC, $\mathrm{FEV}_{1}$ and PEF in the same curve), which included ATS criteria for selection; thus all the criteria were simultaneously present in the same curve, emphasizing the usefulness of

TABLE 6

Sensitivity (\%), specificity (\%) and predictive value (\%) of FVC parameters for the presence of at least one respiratory symptom in the four categories, each composed of the whole sample of 1147 subjects

\begin{tabular}{|c|c|c|c|c|c|c|c|c|c|c|c|c|}
\hline & \multicolumn{3}{|c|}{ Category 1} & \multicolumn{3}{|c|}{ Category 2} & \multicolumn{3}{|c|}{ Category 3} & \multicolumn{3}{|c|}{ Category 4} \\
\hline & Sens & Spec & PV & Sens & Spec & PV & Sens & Spec & PV & Sens & Spec & PV \\
\hline FVC (L) & 8.7 & 94.8 & 30.9 & 8.7 & $\underline{95.0}$ & 31.8 & 9.5 & 94.6 & 31.9 & 10.8 & 94.0 & $\underline{32.5}$ \\
\hline $\mathrm{FEV}_{1}(\mathrm{~L})$ & 19.9 & 94.6 & 49.5 & 20.3 & 93.7 & 46.2 & 19.9 & 94.7 & $\underline{50.0}$ & $\underline{21.6}$ & 93.5 & 46.8 \\
\hline $\mathrm{FEF}_{25-75 \%}$ (L/s) & 21.6 & 93.8 & 48.1 & $\underline{23.2}$ & 93.2 & 47.5 & 22.0 & 94.0 & 49.5 & $\underline{23.2}$ & 92.6 & 45.5 \\
\hline $\mathrm{FEF}_{75-85 \%}(\mathrm{~L} / \mathrm{s})$ & 18.3 & 94.9 & 48.9 & 19.5 & 94.5 & 48.5 & 18.3 & 95.3 & $\underline{50.6}$ & 19.5 & 94.5 & 48.5 \\
\hline MEF50\% (L/s) & 30.7 & 90.2 & 45.4 & 30.3 & 89.6 & 43.7 & 30.3 & $\underline{90.6}$ & $\underline{46.2}$ & $\underline{32.0}$ & 89.1 & 43.8 \\
\hline MEF75\% (L/s) & 25.3 & 92.1 & 45.9 & $\underline{27.4}$ & 91.6 & 46.5 & 24.3 & $\underline{92.4}$ & 46.5 & 25.3 & 91.5 & 44.2 \\
\hline $\operatorname{PEF}(\mathrm{L} / \mathrm{s})$ & 37.3 & 81.9 & 35.4 & $\underline{39.0}$ & 80.9 & 35.2 & 34.9 & 82.7 & 34.9 & 30.3 & $\underline{87.4}$ & $\underline{39.0}$ \\
\hline
\end{tabular}

Category 1 signifies American Thoracic Society criteria 'best test' curve; Category 2 signifies the curve with the largest forced vital capacity (FVC); Category 3 signifies the curve with the largest forced expiratory volume in $1 \mathrm{~s}$ (FEV 1 ); Category 4 signifies the curve with the largest peak expiratory flow (PEF). The highest values for sensitivity (Sens), specificity (Spec) and predictive value (PV) reached by each parameter in categories 1 to 4 are underlined. Sensitivity differences were not statistically different by t test. FEF $25-75 \%$ Forced expiratory flow between $25 \%$ and $75 \%$ of FVC; FEF $75-85 \%$ Forced expiratory flow between $75 \%$ and $85 \%$ of FVC; MEF50\% Maximal expiratory flow at 50\% of FVC; MEF75\% Maximal expiratory flow at $75 \%$ of FVC 
ATS criteria in selecting the best performed manoeuvre, ie, that with maximal effort. Nevertheless, ATS recommendations do not include PEF among the selection criteria (1-3), and an FVC manoeuvre accomplished with submaximal effort may be selected as 'best' curve.

The methods proposed by Quanjer et al (12) do not seem to improve the selection criteria for the 'best' FVC. The first (envelope method) is based on a theoretical FVC curve. As demonstrated by Bouhuys and Jonson (23) and confirmed by Knudson et al (20), one would obtain an FVC curve with higher maximal flow values than those measured from any single FVC curve actually exhaled by the subject. Thus, diagnostic interpretation would be based on a model, rather than the actual, FVC manoeuvre. On the other hand, the second method proposed by Quanjer et al (12) uses three different curves to select the highest instantaneous flows. This might mean that, for example, PEF is obtained from one flowvolume curve and MEF50\% from another. Selecting instantaneous flows in this way would lead to higher intra-individual variability and an underestimation of abnormality. In fact, many patients with severe airflow obstruction yield better results for $\mathrm{FEV}_{1}$ and midexpiratory flow rates when they make submaximal efforts, thereby avoiding airway collapse. Thus, the sensitivity of an FVC manoeuvre might be decreased were this method to be used.

Group 2 and group 3 criteria did not select curves that were representative of the best FVC data. In group 2 (isolated largest $\mathrm{FVC}$ ), $\mathrm{FEV}_{1}$ and all the other derived parameters were lower compared with the ATS- $\Sigma$ curve, because the computation points for mean and instantaneous expiratory flows were shifted towards the right of the flow-volume curve, ie, towards residual volume. In these FVC trials, the submaximal expiratory effort, as demonstrated by a lower mean value in PEF, probably reduced the dynamic expired gas compression with a consequent delay in peripheral airway closure $(9,10)$. In group 3 (isolated largest $\mathrm{FEV}_{1}$ ), the smallest group, higher values for derived flows were obtained than in the ATS- $\Sigma$ curves. In these manoeuvres, subjects expired from TLC, but they were not able to empty their lungs completely; thus, the highest value for FVC was not reached and the computation points for mean and instantaneous expiratory flows were shifted towards the left of the flow-volume curve. In addition, submaximal expiratory effort (indicated by a lower mean value in PEF) was present in this group. Thus, large errors may result in the extrapolated volume and consequently, higher mean values of $\mathrm{FEV}_{1}$, and mean and instantaneous expiratory flows are obtained, if this criterion is applied.

The group 4 criterion, based on the largest PEF, would meet the ATS definition of FVC (1-3), since the highest PEF represents the maximal effort made to perform an FVC manoeuvre. This group contained the lowest FVC, FEV 1 and mean and instantaneous forced expiratory flows, indicating the effects of the airways compression achieved by maximal effort and distinguishing a forced from a slow vital capacity.

Within groups 2, 3 and 4, FVC and derived parameters were significantly different between the ATS curve and the alternative criterion. Therefore, the classification of subjects as normal or abnormal may change, especially if the percentage predicted value of the observed parameter was near the normal $95 \%$ percentile threshold. In our study, the group 4 criterion showed the highest number of abnormalities for $\mathrm{FVC}, \mathrm{FEV}_{1}, \mathrm{FEF}_{75-85 \%}$ and $\mathrm{MEF} 50 \%$, while group 1 showed the highest number of abnormalities for $\mathrm{FEF}_{25-75 \%}$ and MEF $50 \%$.

It is noteworthy that the highest sensitivity for $\mathrm{FEV}_{1}$ in detecting symptomatic subjects was present in group 4 (27.9\%), followed by group 1 (23.0\%). Further, group 4 showed the highest specificity for MEF50\%, MEF $75 \%$ and PEF. Indeed, the highest predictive value for derived flows, in separating symptomatic from asymptomatic subjects, was always shown by group 4 , while the highest predictive value for $\mathrm{FVC}$ and $\mathrm{FEV}_{1}$ was exhibited by groups 3 and 1, respectively, followed by group 4 .

The study design based on the four mutually exclusive groups was adopted in order to have data without overlapping selection criteria and, possibly, to group subjects with similar respiratory pathophysiological conditions. Nevertheless, when analyses were performed on subjects grouped into the four categories constituted by the whole sample of 1147 subjects, analogous results were obtained.

Differences in sensitivity among groups and categories were not statistically significant by $t$ test. However, in this general population sample living in a rural unpolluted area with a low prevalence of respiratory symptoms (17), a clinically useful trend towards an increase in sensitivity in detecting symptomatic subjects was obtained with the use of the largest PEF criterion. Indeed, poor sensitivity and high specificity are two recognized features of the FVC test. For example, Stenton et al (24), during a program of asthma surveillance in the workplace, found a sensitivity of $21 \%$ and a specificity of $92 \%$ for any abnormal ventilatory function test.

Selection methods for values of $\mathrm{FEV}_{1}$ and $\mathrm{FVC}$, based on the manoeuvre with the largest FVC, the largest $\mathrm{FEV}_{1}$ or the largest PEF, were analyzed by Wise et al (25). These authors found that none of the assessed selection methods was substantially superior to any of the others with respect to short term reproducibility of $\mathrm{FEV}_{1}$ and $\mathrm{FVC}$ (coefficient of variation ranging from $4.1 \%$ to $4.9 \%$ and from $3.5 \%$ to $5.7 \%$, respectively). These authors stated that the similarity of the results attested to the overall reproducibility of spirometric measurements when performed with good technique. However, it should be noted that Wise et al (25) suggested caution in extrapolating from this highly selected group to a clinical or general population sample; also, they did not evaluate the relationship of spirometric indexes to the presence of respiratory symptoms. Conversely, we have shown in a general population sample that the selection of the spirogram to be used for interpretative purposes should be based also on its ability to distinguish subjects with symptoms or disease from those without. As demonstrated in Table 5, the criterion of the largest PEF increases by about $5 \%$ the sensitivity of FEV 1 in selecting subjects with the presence of at least one respiratory symptom compared with the group 1 criterion. This im- 
plies that, as regards the $\mathrm{FEV}_{1}$ selected by applying the group 4 criterion, a physician might consider starting or modifying medical treatment in about 5\% more subjects with symptoms.

In a previous paper, we reported that if a combination of lung function indexes were considered, such as the forced spirograms, single breath nitrogen test and diffusing capacity, the percentage of symptomatic male subjects with any lung function abnormality increased to $60 \%$ to $65 \%$ (18). In routine clinical use, the FVC test is often applied to evaluate lung function of subjects with respiratory symptoms. It is possible that, if $\mathrm{PEF}$ were included in the selection criteria for the best FVC curve, the discriminative power of spirograms would be further enhanced. Indeed, subjects in the group selected by the largest PEF criterion tended to have the highest prevalence rates of respiratory symptoms and disease.

In conclusion, our results show that, although the criteria recommended in ATS statements for FVC acquisition have good screening power, this power might be improved by inclusion of PEF in the selection criteria for making the choice of which flow-volume curve to use in an individual. Thus, while maintaining current ATS criteria of acceptability and reproducibility of the FVC manoeuvre, we propose also that the curve that best reflects maximal expiratory effort, ie, that with the largest PEF, be recorded and analyzed, thereby improving early detection of COPD, a condition whose morbidity and mortality are still increasing (26).

ACKNOWLEDGEMENTS: We thank Dr Norman L Jones of McMaster University, Hamilton, Ontario for his invaluable suggestions. This work was supported in part by the Italian National Research Council (CNR), Targeted Project "Prevention and Control Disease Factors - SP2 - Contract 91.00171.PF41", by the Health Departments of the Veneto and Emilia Romagna Regions, by a grant of the Italian Electric Power Authority (ENEL), by the CNRENEL Special Project "Interactions of Energy System with Human Health and Environment", Rome, Italy, and by Contract $\mathrm{N}^{\mathrm{O}}$ BMH1-CT92-0849 (BIOMED 1) between the European Economic Community and the University of Pisa, Italy.

\section{REFERENCES}

1. Gardner RM, Baker CD, Broennle AM. ATS Statement: Snowbird workshop on standardization of spirometry. Am Rev Respir Dis 1979;119:831-8

2. Gardner RM, Hankinson JL, Clausen JL, Crapo RO, Johnson RL Jr, Epler GR. American Thoracic Society. Standardization of spirometry 1987 Update. Am Rev Respir Dis 1987;136:1285-98.

3. Crapo RO, Hankinson JL, Irvin C, MacIntyre R, Voter KZ, Wise RA. American Thoracic Society. Standardization of spirometry: 1994 update. Am J Respir Crit Care Med 1995;152:1107-36.

4. Cotes JE. Lung Function, 4th edn. London: Blackwell Scientific Publications, 1979.
5. Pistelli G, Carmignani G, Paoletti P, et al. A comparison of algorithms for determination of end-point of the forced vital capacity maneuver. Chest 1987;91:100-5.

6. Eisen EA, Robins JM, Greaves IA, Wegman DH. Selection effects of repeatability criteria applied to lung spirometry. Am J Epidemiol 1984;120:734-8.

7. Hankinson JL, Bang KM. Acceptability and reproducibility criteria of the American Thoracic Society as observed in a sample of the general population. Am Rev Respir Dis 1991;143:516-21.

8. Sorensen JB, Morris AH, Crapo RO, Gardner RM. Selection of the best spirometric values for interpretation. Am Rev Respir Dis 1980;122:802-5

9. Krowka MJ, Enright PL, Rodarte JR, Hyatt RE. Effect of effort on measurement of forced expiratory volume in one second. Am Rev Respir Dis 1987;136:829-33.

10. Ingram RH Jr, Schilder DP. Effect of thoracic gas compression on the flow-volume curve of the forced vital capacity. Am Rev Respir Dis 1966;94:56-63.

11. Morris AH, Kanner RE, Crapo RO, Gardner RM. Clinical Pulmonary Function Testing: A Manual of Uniform Laboratory Procedures, 2nd edn. Salt Lake City: Intermountain Thoracic Society, 1984.

12. Quanjer PH, Tammeling GJ, Cotes JE, Pedersen OF, Peslin R, Yernault JC. Lung volumes and forced ventilatory flows. Eur Respir J 1993;6(Suppl 16):5-40.

13. Enright PL, Johnson LR, Connett JE, Voelker H, Buist S. Spirometry in the Lung Health Study: methods and quality control. Am Rev Respir Dis 1991; 143:1215-23.

14. Becklake M, Crapo RO, Buist A. American Thoracic Society. Lung function testing: selection of reference values and interpretative strategies. Am Rev Respir Dis 1991;144:1202-18.

15. Carrozzi L, Giuliano G, Viegi G, et al. The Po River Delta epidemiological study of obstructive lung disease: sampling methods, environmental and population characteristics. Eur J Epidemiol 1990;6:191-200.

16. Paoletti P, Pistelli G, Fazzi P, et al. Reference values for vital capacity and flow-volume curves from a general population study. Bull Eur Physiopathol Respir 1986;22:451-6.

17. Viegi G, Paoletti P, Prediletto R, et al. Prevalence of respiratory symptoms in an unpolluted area of northern Italy. Eur Respir J 1988;1:311-8.

18. Viegi G, Paoletti P, Prediletto R, et al. Carbon monoxide diffusing capacity, other indices of lung function, and respiratory symptoms in a general population sample. Am Rev Respir Dis 1990;141:1033-9.

19. Lilienfeld AM, Lilienfeld DE. Morbidity statistics. In: Foundations of Epidemiology, 2nd edn. Don Mills: Oxford University Press, 1980:133-65.

20. Knudson RJ, Lebowitz MD, Holberg CJ, Burrows B. Changes in the normal maximal flow-volume curve with growth and aging. Am Rev Respir Dis 1983;127:725-34.

21. Suratt PM, Hooe DM, Owens DA, Anne A. Effect of maximal versus submaximal expiratory effort on spirometric values. Respiration 1981;42:233-6.

22. Knudson RJ, Lebowitz MD, Slatin RC. The timing of the forced vital capacity. Am Rev Respir Dis 1979;119:315-8.

23. Bouhuys A, Jonson B. Alveolar pressure, airflow rate, and lung inflation in man. J Appl Physiol 1967;22:1086-100.

24. Stenton SC, Beach JR, Avery AJ, Hendrick DJ. The value of questionnaires and spirometry in asthma surveillance programmes in the workplace. Occup Med 1993;43:203-6.

25. Wise RA, Connett J, Kurnow K, et al. Selection of spirometric measurements in a clinical trial, the Lung Health Study. Am J Respir Crit Care Med 1995;151:675-81.

26. Feinleib M, Rosenberg HM, Collins JG, Delozier JE, Pokras R, Chevarley FM. Trends in COPD morbidity and mortality in the United States. Am Rev Respir Dis 1989;140:S9-18. 


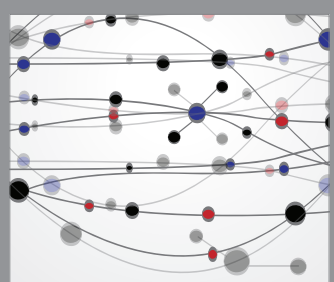

The Scientific World Journal
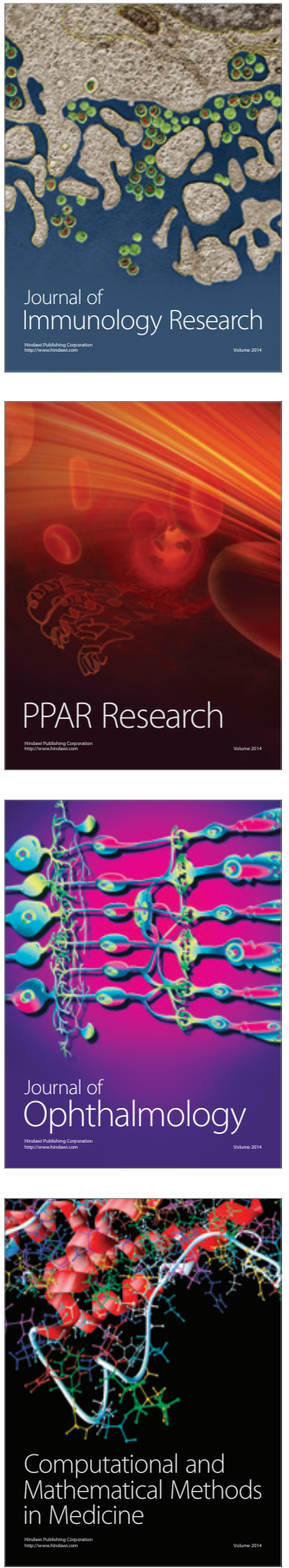

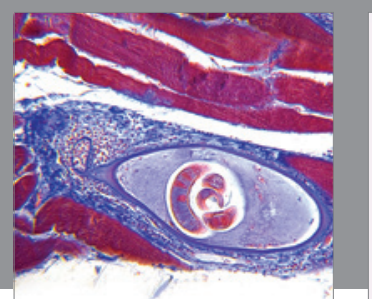

Gastroenterology Research and Practice

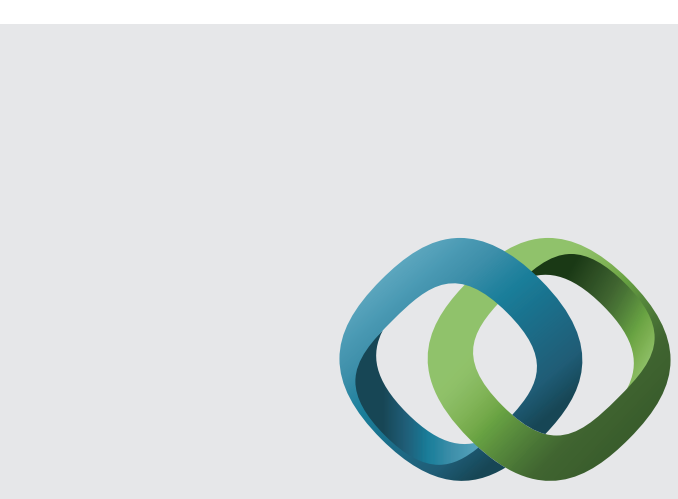

\section{Hindawi}

Submit your manuscripts at

http://www.hindawi.com
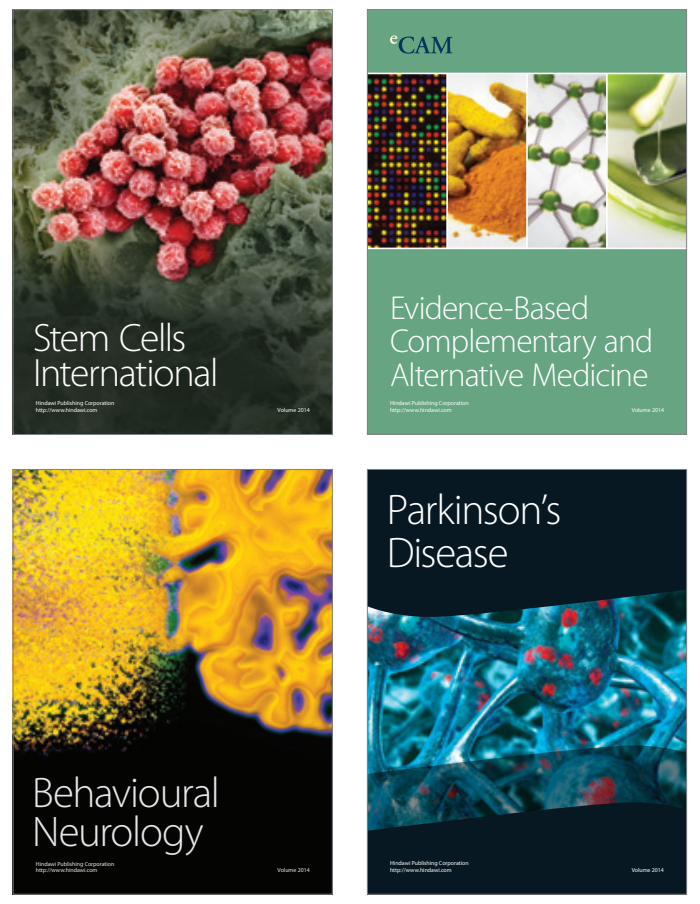
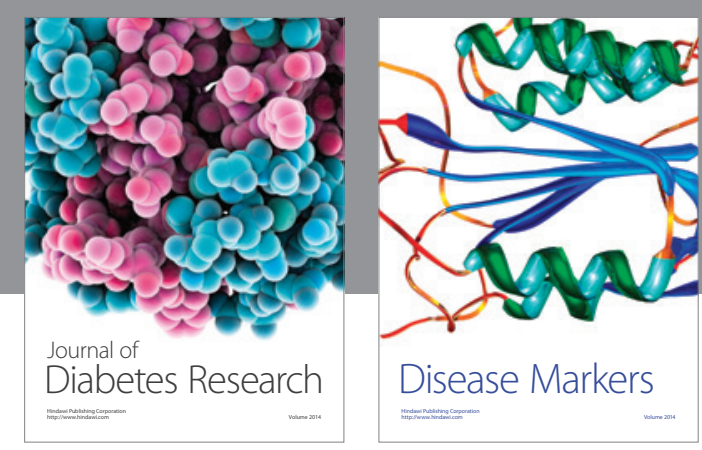

Disease Markers
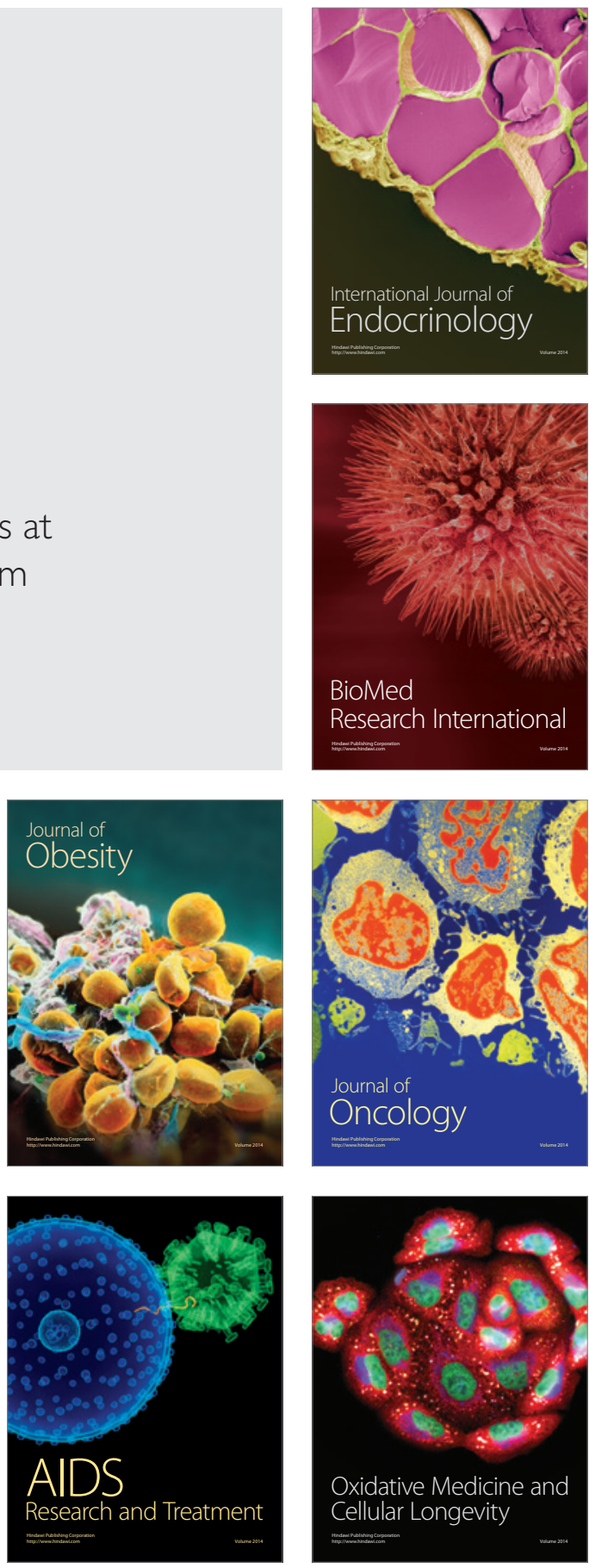